2||-||||||||||||||||||||||||||||||||||||||||||||||||||||||||||||||||||.

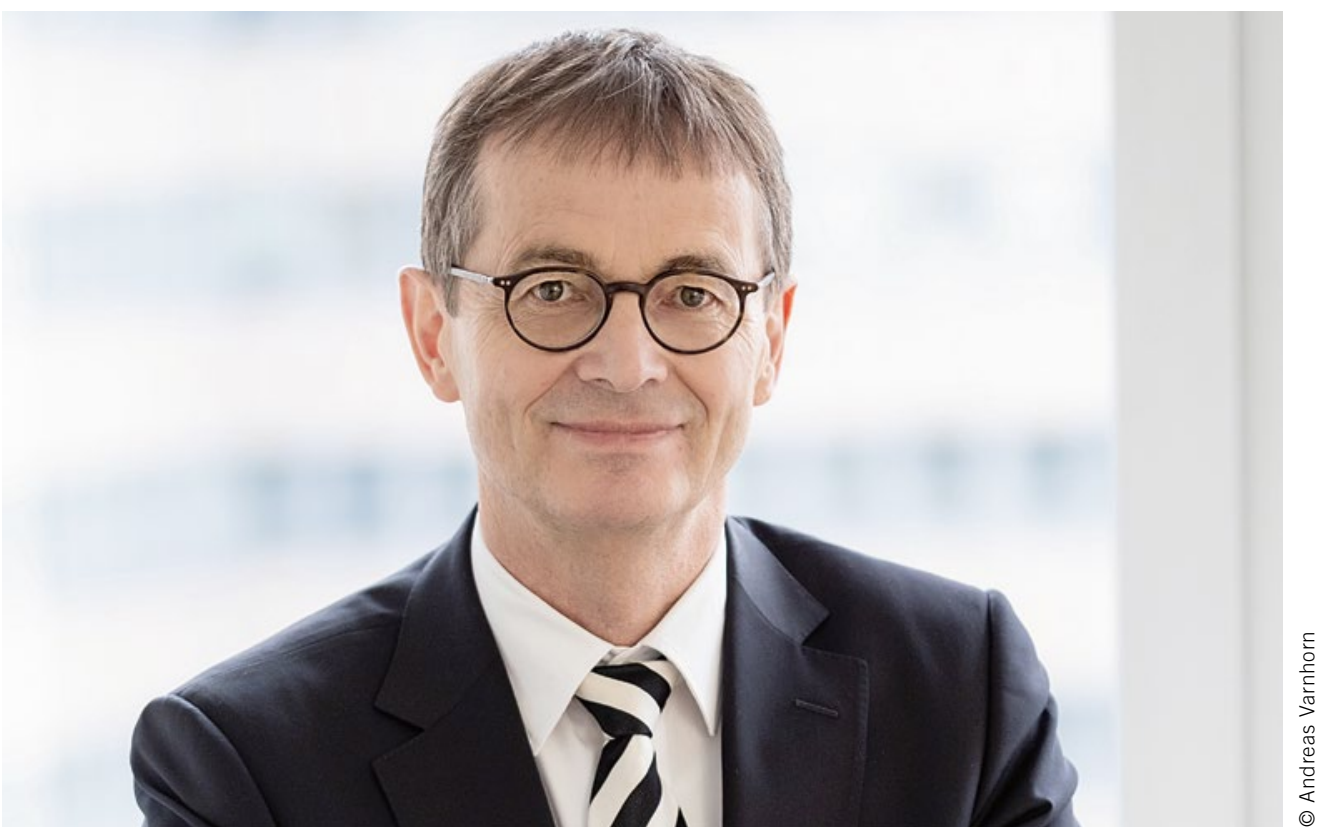

Dr. Bernd Scherer

Managing Director of the Agricultural Engineering

Association of the VDMA in

Frankfurt (Germany)

\title{
$40 \%$ Less Fuel - Thanks to Cool Heads Instead of a Heavy Foot on the Accelerator
}

Frequent drivers of automobiles are all too familiar with the deceptive belief that an increased pace will result in a faster arrival. This is usually an illusion, since a brisk foot on the accelerator pedal rarely achieves more than a considerable bill at the next filling station. The situation appears similar yet different for fields, farm tracks and country roads, where agricultural machinery and tractors are moving in tough work and transport environments. Here too, the driver plays a central role in terms of ensuring climate-friendly processes. However, the difference is that agriculture is concerned not merely with the distance traveled, but more importantly with the generated yields.

In a research project on fuel efficiency in agricultural machinery, financed by the German Federal Ministry of Agriculture, scientific, industry and trade association experts have investigated the fuel-related carbon footprint of agriculture over the past three years. The focus was logically placed on agricultural fuel requirements in relation to the actual yield from the fields. The results are now available and show the changes that are taking place in agricultural machinery: Since 1990, the beginning of the period under investigation, fuel requirements for the production of $1 \mathrm{t}$ of wheat have decreased by as much as $30 \%$. As a maximum, by the year 2030 this figure may even reach $40 \%$.

What does this tell us? On the one hand, agriculture is heterogenous and depends on procedures, soils, climate and vegetation zones, which must be considered if one wishes to achieve reasonable assessments of the agricultural process. On the other hand, agricultural machinery, the most important enabler of modern agriculture, makes an essential contribution to tapping climate protection potentials. Although they have certainly already reached the limits of physical feasibility in terms of individual machines and their engines, from a dedicated process perspective these potentials are far from exhausted. For instance, optimization of the logistics chain with a focus on tothe-minute timing, intelligent engine management and high throughput makes it possible to produce more with less: more food with less fuel consumption. To cite a pithy sample calculation from the project, today 16,000 bread rolls can already be produced with 11 of diesel.

In addition, there is the role of the driver, as mentioned above. Training drivers effectively and preparing them for clever monitoring of increasingly automated procedures is the task of the industry and its trade partners. However, bringing the technology that can achieve all this into the market with a strong momentum is also a question of adequate policy framework conditions. The right approach comprises fiscal support of investment, attractive bonuses for climate-neutral farmers and deliberate technological openness that takes into consideration alternative fuels and intelligent process solutions as well as electromobility and fuel cells. If we succeed in this, cool heads will have defeated more than just the heavy foot on the accelerator pedal. 